\title{
Reinstatement of Extinguished Conditioned Responses and Negative Stimulus Valence as a Pathway to Return of Fear in Humans
}

\author{
Trinette Dirikx, ${ }^{1}$ Dirk Hermans, Debora Vansteenwegen, Frank Baeyens, \\ and Paul Eelen
}

Department of Psychology, University of Leuven, Leuven 3000, Belgium

\begin{abstract}
The present study investigated reinstatement of conditioned responses in humans by using a differential Pavlovian conditioning procedure. Evidence for reinstatement was established in a direct (fear rating) and in an indirect measure (secondary reaction time task) of conditioning. Moreover, the amount of reinstatement in the secondary reaction time task was significantly correlated with the difference in valence between the conditioned stimulus (CS)+ and the CS- after extinction. These data provide clear evidence for reinstatement and for the role of negative stimulus valence in the return of conditioned responding after extinction.
\end{abstract}

Although extinction used to be conceived of as a process of unlearning of a previously acquired association, numerous contradicting findings have led to a new conceptualization of the mechanisms of extinction. Research has demonstrated that although conditioned responding is attenuated, a lot of what has been learned during acquisition remains unaffected by extinction. First, research shows that extinction does not abolish the original conditioned stimulus (CS)-unconditioned stimulus (US) association, and can even leave this CS-US association intact (see Rescorla 1996). Second, there is ample evidence indicating that the acquired valence of the CS survives extinction (for an overview, see De Houwer et al. 2001).

With respect to the first issue, four phenomena (spontaneous recovery, renewal, rapid reacquisition, and reinstatement) illustrate the preservation of the CS-US association after extinction (see Bouton 2002). This article will focus on "reinstatement," which refers to the return of extinguished conditioned responses due to the experience of one or more US-only presentations after extinction. In sharp contrast with the extensive amount of animal research (see Rescorla and Heth 1975; Bouton and Bolles 1979; Delamater 1997), only little research has been conducted on reinstatement in humans. By using a differential aversive conditioning procedure, Hermans, Dirikx and colleagues were able to demonstrate reinstatement effects in humans (Hermans et al. 2004; T. Dirikx, D. Hermans, D. Vansteenwegen, F. Baeyens, and P. Eelen, in prep.). To our knowledge these experiments provide the first evidence for reinstatement of aversively conditioned responses in humans. Except for some details (e.g., the number of CS presentations), the procedure used in these studies was very similar to the present one. The participants went through the same phases as described below, and the same dependent measures were used.

In addition to the fact that the CS-US association can survive extinction and can hence be the basis for the re-emergence of conditioned responses, we consider the evaluatively conditioned, but extinction-resistant negative valence of the aversively

\footnotetext{
${ }^{1}$ Corresponding author.

E-MAIL Trinette.Dirikx@psy.kuleuven.ac.be; FAX 32-1632-60-99. Article and publication are at http://www.learnmem.org/cgi/doi/10.1101/ Im.78004.
}

conditioned CS+ as a second possible pathway for the return of conditioned responding. Evaluative conditioning refers to changes in stimulus valence due to the pairing of this stimulus with another (positive or negative) stimulus (De Houwer et al. 2001). For instance, in the context of human aversive conditioning, Hermans et al. (2002c) have demonstrated that the CS+ acquires a negative stimulus valence throughout acquisition. It is now well-documented that one of the most important properties of evaluative learning is its resistance to extinction. This has been demonstrated in studies on preference learning in animals (see Elizalde and Sclafani 1990) as well as in different evaluative conditioning preparations in humans (see Baeyens et al. 1988; Hermans et al. 2002b). With respect to the return of conditioned responding after extinction, Hermans et al. (2002c) suggested that the remaining negative valence of the CS+ after extinction might function as an affective-motivational source for the re-emergence of conditioned fear responses. Some preliminary evidence for this hypothesis was obtained in the aforementioned reinstatement studies by Hermans et al. (2004) and T. Dirikx, D. Hermans, D. Vansteenwegen, F. Baeyens, and P. Eelen (in prep.). Although no significant reinstatement effect was established in the reaction time data, in both studies a significant correlation was demonstrated between the valence of the CS+ after extinction and the extent to which a return of differential reaction times was observed after the reinstating USs. The more negative the $\mathrm{CS}_{+}$, the more the reinstatement was demonstrated.

These observations are in accordance with the emotion theory that was proposed by Lang (1995). According to Lang, all emotions can be located in a two-dimensional space, with affective valence (positive/negative) and arousal (high/low) as crucial dimensions. These dimensions interact to constitute different emotions. Against this background, fear can be considered as an emotion characterized by a negative valence and high levels of arousal. If we apply this line of reasoning to the reinstatement procedure, this would mean the following: The extinction procedure leads to a significant decrease in arousal, but leaves the negative stimulus valence intact (cf. Hermans et al. 2002b). The next step in our procedure is to administer unpredictable US-only trials. This reinstatement procedure could be considered as a procedure that essentially endows the context with a higher level of 
arousal (context-conditioning during reinstatement; Bouton 1991). Introducing the still negatively valenced CS+ in this arousing context during test might recombine the negative valence with a higher level of arousal, thus leading to a partial "reinstatement" of the previously extinguished fear responses. In presenting this view on reinstatement, we consider it complementary to Bouton's viewpoint (Bouton 1991) on reinstatement as a result of contextual conditioning of the reinstatement context. We state that stimulus valence might play an important role in explaining interindividual differences in the strength of the reinstatement effect.

The present study replicated and extended our previous findings. First, in the present study reinstatement of aversively conditioned responses was observed, and second, the return of aversively conditioned responses was mediated by the conditioned (negative) stimulus valence. An important extension of the results of the previous studies is that the reinstatement effect could also be demonstrated using a nonverbal measure. More specifically, a secondary reaction time task was used as a measure of conditioned responding (based on Dawson et al. 1982). This task involves the presentation of tone probes during the presentation of the CSs. It has previously been demonstrated (see Dawson et al. 1982) that reaction times are slowed down on probes that are presented during $\mathrm{CS}_{+}$, compared with probes presented during the $\mathrm{CS}-$, which is attributed to allocation of processing resources toward the CS+. This difference was predicted to disappear during extinction and to selectively reappear in the reinstatement group during test. The results of the present study show exactly this pattern of results. As such, the present results rule out the possibility that the reinstatement effects were (partly) due to demand effects. This was a limitation of the previous studies (Hermans et al. 2004; T. Dirikx, D. Hermans, D. Vansteenwegen, F. Baeyens, and P. Eelen, in prep.) in which the effect of reinstatement could only be demonstrated in the verbal reports.
Because the crucial acquisition and extinction effects did not interact with the between-subjects variable "condition," we combined both groups for the analyses concerning these first two phases. The data from the verbal ratings were analyzed by using a two-by-two univariate ANOVA with CS-type (CS+/CSa) and Moment (combinations of preacquisition, postacquisition, postextinction, and post-reinstatement) as within-subjects variables. Wherever available, the ratings were compared with a previous rating (e.g., postextinction rating with postacquisition rating to test for extinction). For the data that concerned the test phase, a similar ANOVA was carried out but with the between-subjects variable "condition" (control/reinstatement group) included in the analyses. The results were further examined by using contrast analyses. With respect to the secondary reaction time task, all reaction times $>1000 \mathrm{msec}$ and $<200 \mathrm{msec}$ were excluded from the analyses to reduce the influence of outlier responses. An $\alpha$ level of 0.05 was used for all statistical tests.

In all of our dependent measures, significant acquisition effects were demonstrated. All relevant means are presented in Table 1 . First, the acquisition data of the secondary reaction time task were analyzed by using a 2 (block, 1/2) $\times 2$ (CS: CS+/CSa) $\times 2$ (probe position: early/late) ANOVA. A significant main effect of CS was observed, $F_{(1,20)}=8.19, M S E=24069$, with significantly slower reaction times on probes that were presented during the CS+ compared with probes presented during the CS- ${ }_{\mathrm{a}}$. Confirming the data of this indirect measure, following acquisition the participants demonstrated significantly higher US expectancy ratings for the CS+ compared with the CS-a, $F_{(1,31)}=122.10, M S E=826$. Hence, because of the acquisition procedure, the CS+ became a valid predictor of the US. Because preacquisition ratings of valence and fear were collected, the acquisition effects for these variables were evaluated by comparing the postacquisition ratings with the preacquisition ratings. The

Table 1. Overview of the Means of All Dependent Variables

\begin{tabular}{|c|c|c|c|c|c|c|c|c|}
\hline & \multicolumn{2}{|c|}{ Preacquisition } & \multicolumn{2}{|c|}{ Acquisition } & \multicolumn{2}{|c|}{ Extinction } & \multicolumn{2}{|c|}{ Test } \\
\hline & $\mathrm{CS}_{+}$ & CS- & $\mathrm{CS}_{+}$ & CS-a & CS+ & CS-a & $\mathrm{CS}_{+}$ & CS-a \\
\hline \multicolumn{9}{|l|}{ US expectancy } \\
\hline Reinstatement & & & 88.82 & 18.82 & 24.71 & 3.53 & 50.00 & 22.35 \\
\hline Control & & & 96.67 & 6.67 & 12.00 & 4.00 & 10.00 & 2.00 \\
\hline Total & & & 92.50 & 13.13 & 18.75 & 3.75 & 31.25 & 12.81 \\
\hline \multicolumn{9}{|l|}{ Fear } \\
\hline Reinstatement & 0.00 & 0.24 & 5.71 & 0.88 & 2.76 & 0.47 & 4.24 & 1.76 \\
\hline Control & 0.07 & 0.36 & 5.64 & 0.86 & 2.93 & 0.50 & 1.73 & 0.87 \\
\hline Total & 0.03 & 0.29 & 5.68 & 0.87 & 2.84 & 0.48 & 3.06 & 1.34 \\
\hline \multicolumn{9}{|l|}{ Valence } \\
\hline Reinstatement & 0.50 & 1.56 & -2.81 & 1.63 & -1.31 & 1.63 & -2.65 & 1.06 \\
\hline Control & 1.13 & -0.93 & -3.33 & -0.33 & -2.47 & -1.33 & -1.75 & -0.94 \\
\hline Total & 0.81 & 0.35 & -3.06 & 0.68 & -1.87 & 0.19 & -2.21 & 0.09 \\
\hline Secondary RT task & & & & & \multicolumn{2}{|c|}{ Last Block } & \multicolumn{2}{|c|}{ First Block } \\
\hline \multicolumn{5}{|l|}{ Reinstatement } & & & \multirow{4}{*}{\multicolumn{2}{|c|}{479}} \\
\hline Block 1 & & & 589 & 560 & \multirow[t]{3}{*}{430} & \multirow[t]{3}{*}{450} & & \\
\hline Block 2 & & & 605 & 545 & & & & \\
\hline Mean block 1 and 2 & & & 597 & 573 & & & & \\
\hline \multicolumn{9}{|l|}{ Control } \\
\hline Block 1 & & & 633 & 536 & 369 & 369 & 425 & 411 \\
\hline Block 2 & & & 615 & 478 & & & & \\
\hline Mean block 1 and 2 & & & 624 & 507 & & & & \\
\hline Total & & & 610 & 542 & 401 & 411 & 515 & 448 \\
\hline
\end{tabular}

The presented means concern the data that were part of the crucial ANOVA concerning the particular phase [e.g., the mean postextinction fear rating for the CS $\div$ concerns the participants that were included in the 2 (Moment: postacquisition/postextinction) $\times 2$ (CS) ANOVA for the fear ratings]. 
Moment (preacquisition/postacquisition) $\times$ CS interaction proved to be significant for the fear ratings, $F_{(1,30)}=44.51$, $M S E=4.47$, indicating that the increase in fearfulness was stronger for the CS+, $F_{(1,30)}=86.89, M S E=5.68$, than for the CS-a, $F_{(1,30)}=5.45, M S E=0.96$. The evaluative ratings show that the conditioning procedure also led to changes in the valence of the stimuli. The Moment (preacquisition/postacquisition) $\times$ CS interaction proved to be significant, $F_{(1,30)}=19.36, M S E=7.04 .^{2}$

Next the extinction data were analyzed. The reaction time data of the extinction phase were analyzed by using a 2 (block: last acquisition block/the last extinction block; for the participants who received extra extinction blocks, the data of block 5 were analyzed, whereas for the other participants, the last extinction block was block 3$) \times 2(\mathrm{CS}) \times 2$ (probe position) ANOVA. The block $\times$ CS interaction proved to be significant, $F_{(1,24)}=14.60, M S E=8779$, resulting in the disappearance of the main effect of $\mathrm{CS}$ in the last extinction block, $F<1$. Extinction was also clearly demonstrated in the US expectancy and fear ratings (For the participants who received extra extinction blocks, the analyses of all postextinction ratings concerned the ratings after the extra blocks). The Moment (postacquisition/ postextinction) $\times \mathrm{CS}$ interaction proved to be significant for US expectancy, $F_{(1,31)}=62.30, M S E=532$, and for fear $F_{(1,30)}=14.88$, $M S E=3.13$, indicating differential changes for the CS+ and the $\mathrm{CS}_{-}$. Despite these changes, the difference between the CS+ and $\mathrm{CS}_{-\mathrm{a}}$ remained significant after extinction, both for the US expectancy ratings, $F_{(1,31)}=14.49, M S E=248$, and the fear ratings, $F_{(1,30)}=22.71, M S E=3.78$. With regard to the US expectancy ratings, the condition $\times$ Moment $\times$ CS interaction proved to be significant, $F_{(1,30)}=4.60, M S E=477$. The Moment $\times$ CS interaction was significant for both conditions, but this effect was more pronounced in the control group, $F_{(1,30)}=52.88, M S E=477$, than in the reinstatement group, $F_{(1,30)}=21.25, M S E=477$. With regard to the evaluative ratings, the CS+, $F_{(1,30)}=5.79, M S E=$ 3.81 , changed in valence from the postacquisition to the postextinction rating but the CS-a did not, $F_{(1,30)}=1.40, M S E=2.60, P$ $=0.25$. The Moment (postacquisition/postextinction) $\times$ CS interaction was significant, $F_{(1,30)}=6.98, M S E=3.12$. Again we refer to Table 1 for an overview of all relevant means. Thus, after acquisition and extinction, all preconditions for investigating reinstatement were met. In all dependent measures, significant acquisition effects were demonstrated, and extinction was established in the secondary reaction time task, the fear ratings, and the US expectancy ratings. In contrast to, for example, Hermans et al. (2002b), in the present study extinction was also demonstrated in the evaluative ratings.

To test for reinstatement, the data of the secondary reaction time task were analyzed by using a 2 (group: reinstatement/ control group) $\times 2$ (block: last extinction block/first test block) $\times 2$ (CS) ANOVA (Fig. 1). The analysis of the two-way interactions for both levels of the between groups variable provided strong evidence for reinstatement. The block $\times$ CS interaction proved to be highly significant for the reinstatement group, $F_{(1,24)}=8.04, M S E=8763$. A comparison between the last extinction block and the first test block showed a strong increase in reaction times on probes presented during the CS+, $F_{(1,24)}=11.67, M S E=15594$, whereas no such change was present for probes presented during the CS-a, $F<1$. This differential

${ }^{2}$ For four participants, the CSs chosen during the stimulus-selection phase were not among the most neutral due to a procedural error. Two participants started acquisition with a difference in valence between the CS+ and CS-a in the direction that we would expect after acquisition. When these two participants are discarded from the analyses, the Moment $\times$ CS interaction remained highly significant, $F_{(1,28)}=16.32, M S E=7.11$.

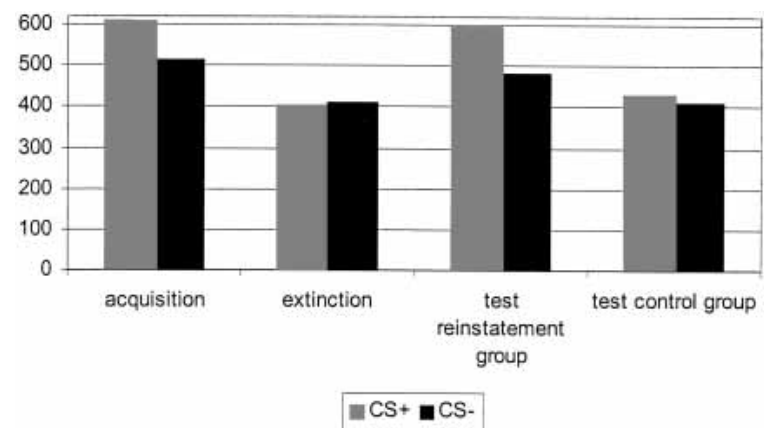

Figure 1 Reaction times on probes presented during the CS+ and CSduring the last acquisition block, the last extinction block, and the first test block.

change in reaction times led to the re-emergence of the effect of the CS variable in the first test block, $F_{(1,24)}=7.03, M S E=12308$. In contrast with these data, the control group did not show any changes when the last extinction block was compared with the first test block. There were no changes in reaction times, not for the CS+ or for the CS-a, $F<1$. The block $\times$ CS interaction was not significant, $F<1$, and no effect of CS could be observed during test, $F<1$. The crucial three-way interaction, which summarizes the data for both groups, just failed to reach statistical significance, $F_{(1,24)}=3.4, P=0.08, M S E=8763$. In addition to the data of the secondary reaction time task, reinstatement was also established in the fear ratings (Fig. 2). In line with the predictions, the crucial condition $\times$ Moment $\times$ CS interaction proved to be significant, $F_{(1,30)}=4.87, M S E=1.02$. Looking at the data for the control participants separately revealed a continuation of extinction in this group. The Moment (postextinction/test) $\times \mathrm{CS}$ interaction was significant, $F_{(1,30)}=7.23, M S E=1.02$. Whereas after the extinction phase there had remained a significant difference between the CS+ and the CS-a, both stimuli were equally fearful at the test rating, $F_{(1,30)}=1.82, P=0.19, M S E=3.1$. The Moment $\times$ CS interaction was not significant in the reinstatement group, $F<1$, but a third way of looking at the data, namely, analyzing the condition $\times$ Moment interactions for each level of the CS variable clearly demonstrates the successfulness of our manipulation. The condition $\times$ Moment interaction was significant for the CS+, $F_{(1,30)}=10.12, M S E=2$. The reinstatement manipulation had a differential effect on the fearfulness of the $\mathrm{CS}+$, in that the fear of the CS+ increased significantly in the reinstatement group, $F_{(1,30)}=7.65, M S E=3.87$, whereas a marginally significant decrease was observed in the control group, $F_{(1,30)}=3.12, P=0.09, M S E=2.4$. Contrary to these results

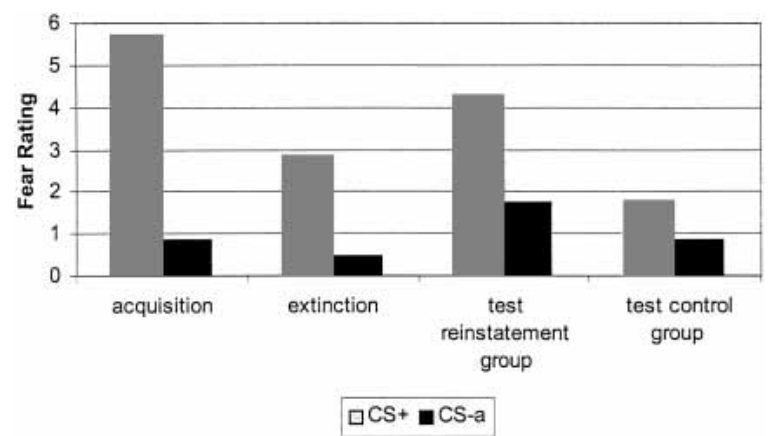

Figure 2 Fearfulness of the $\mathrm{CS}_{+}$and $\mathrm{CS}_{-}$after acquisition, extinction and test. 
for the $\mathrm{CS}+$, the condition $\times$ Moment interaction was not significant for the control stimulus, $F_{(1,30)}=2.05, P=0.16$, $M S E=1.55$. The reinstatement effects observed in the secondary reaction time task and the fear ratings could not be replicated in the US expectancy ratings. The condition $\times$ Moment $\times$ CS interaction was not significant, $F<1$, nor was the twoway interaction for the reinstatement group, $F_{(1,30)}=1.29$, $P=0.27, M S E=138$. Both for the CS $+, F_{(1,30)}=5.69, M S E=472$, and the CS-a, $F_{(1,30)}=5.85, M S E=224$, a significant condition $\times$ Moment interaction was observed, indicating that the reinstatement procedure did not selectively affect the CS+ but also increased responding to the CS-a. An overview of the relevant means concerning the test phase is presented in Table 1.

To test our hypothesis concerning the relationship between stimulus valence and return of fear, a correlational analysis was carried out. As expected, for the reinstatement group a significant correlation was demonstrated between the difference in valence between the CS+ and $\mathrm{CS}_{-}{ }_{\mathrm{a}}$ after extinction on the one hand (the rating for the CS- ${ }_{\mathrm{a}}$ was subtracted from the rating for the $\mathrm{CS}+$ ), and the amount of reinstatement observed in the secondary reaction time $\operatorname{task}^{3}$ one the other hand $(r=-0.59$, $P<0.05)$. This correlation was not significant in the control group $(P=0.17)$. No similar relationship was observed with the residual difference in US expectancy after extinction $(r=0.29$, $P=0.32$ ). The correlation between the amount of reinstatement in the RT data and the difference in fear of the CS+ and CS-a after extinction, however, was marginally significant $(r=0.48$, $P=0.08)$. In line with the emotion theory by Lang (1995), we believe that the fear rating might tap a combination of both the evaluative as well as the arousing characteristics of the CSs. Therefore, it is not surprising that the correlation with the fear rating goes in the same direction as the one for the evaluative (valence) rating.

Our data indicate that for the participants who received reinstating USs and thus experience the context as dangerous, the extent to which they show reinstatement is related to the difference in valence between the CS+ and CS-a after extinction.

A total of 46 participants ( 20 women) volunteered to participate in this study. Because knowledge of the relevant contingencies $(\mathrm{CS}+/ \mathrm{US}, \mathrm{CS}-/-)$ was considered to be a necessary precondition for the study of a return of conditioned responses, only participants who were contingency aware, were included in the analyses. As a result, the data of 13 participants were eliminated from the analyses because these persons did not reach our criterion for contingency-awareness. Seventeen of the 33 remaining participants (14 women) were assigned to the reinstatement group, and the other 16 participants formed the control group.

All stimuli used were selected from a set of 20 color pictures of human faces (see Hermans et al. 2002c) and were presented on a computer screen. The US was an electrocutaneous stimulus that was administered to the left wrist. Fukuda standard Ag/AgCl electrodes (1.2-cm diameter) were filled with K-Y jelly. Reaction time probes were $100-\mathrm{Hz}$ tones with a duration of $2000 \mathrm{msec}$. The administration of all stimuli and the registration of the ratings

\footnotetext{
${ }^{3}$ The amount of reinstatement in the secondary reaction time task was calculated as follows: Both for the last extinction block and the first test block, the reaction times for probes presented during the CS-a were subtracted from the reaction times during the $\mathrm{CS}+$. Next, the extinction difference-score was subtracted from the test difference score to obtain an index for reinstatement. Positive differences are thus indicative for a greater difference in reaction times between the $\mathrm{CS}+$ and the $\mathrm{CS}_{-}$a during the first test block than during the last extinction block, with slower reaction times during the CS+ than during the CS-a.
}

and RTs were controlled by a program that was constructed with Affect 3.0, a Windows-based software package (Hermans et al. 2002a). Before the start of the experiment, the participants were informed about the use of electrocutaneous stimuli and about the fact that they could end their participation at any moment during the experiment. All participants gave written informed consent.

The dependent variables in the present study were verbal ratings and reaction times on probes presented during the CSs. Evaluative ratings and fear ratings of all 20 pictures were administered before the start of the experiment. After the acquisition phase, contingency awareness was assessed. Participants were considered to be contingency aware if they could correctly identify the CS+ and CS - and were at least "reasonably certain" of their choice. The acquisition, extinction, and test phases were each followed by a rating phase. These rating phases took $\sim 2$ to 3 min. First, each CS was rated on an 11-point scale ranging from "not at all" to "very much" for the amount of US expectancy that was associated with it. Similarly, fear ratings were obtained for every CS. For the acquisition and extinction phases, these ratings referred to the last presentations of the stimuli. For the reinstatement phase, these ratings referred to the crucial test trials (i.e., the first presentations of the test phase). Finally, every picture was evaluatively rated by using an 21-point rating scale that ranged from -10 (very unpleasant) to 10 (very pleasant), with zero as the neutral midpoint (evaluative rating). With regard to the secondary reaction time task, half of the probes appeared 300 msec after stimulus onset (early probes), whereas the other half was administered $6000 \mathrm{msec}$ after CS onset (late probes). During the acquisition and the extinction phase, half of the CSs were administered with a tone probe, whereas during the test (of reinstatement) phase probes were presented with all pictures. The participants were asked to press the space bar as quickly as possible when the tone was presented. The experiment thus consisted of five phases: stimulus selection, acquisition, extinction, reinstatement, and test. An overview of the different phases and their duration is presented in Figure 3.

At the start of the stimulus-selection phase, the intensity of the electrocutaneous stimulus was set for each participant individually. We asked the participant to choose an intensity that was "unpleasant and demanding some effort to tolerate." All 20 pictures were rated for valence and for the amount of fear that was evoked by the pictures. Based on these ratings, the two among the neutral pictures of this set were chosen to be the CS+ and CS- ${ }_{\mathrm{a}}$. The CS- ${ }_{\mathrm{a}}$ was considered to be the crucial control stimulus to compare with the CS+. Four other pictures served as CS-b, CS-c, and filler stimuli. A previous study had shown that if only one control stimulus was used, this easily led to participants expecting a reversal of the contingency after extinction. Therefore, we preferred to use multiple control stimuli to reduce the saliency of the CS-a.

During acquisition each CS was administered eight times. The duration of each presentation was $7000 \mathrm{msec}$. The CS+ was always immediately followed by an electrocutaneous stimulus with a duration of $1500 \mathrm{msec}$. The three CS-s were never followed by the US. The intertrial interval (ITI) ranged between 3000 and $4000 \mathrm{msec}$, with a mean of $3500 \mathrm{msec}$. The acquisition phase consisted of two (semirandomized) blocks of 16 trials. The restriction on randomisation was that the first block always started with the administration of each of the four CSs in randomized order.

During extinction no USs were administered. The phase consisted of three experimental blocks; every CS was presented 12 times during extinction. The first extinction block started with a CS - . Otherwise the procedure was similar to the acquisition phase (e.g., probe presentations). For those participants that 


\begin{tabular}{|c|c|c|}
\hline Phase & Duration & Events \\
\hline Stimulusselection & $20 \mathrm{~min}$ & $\begin{array}{l}\text { Choice US-intensity } \\
\text { Choice CSs and filler stimuli based on } \\
\text { an evaluation and fear rating of } 20 \\
\text { pictures }\end{array}$ \\
\hline \multirow[t]{2}{*}{ Acquisition } & $5 \min 43 s$ & $\begin{array}{l}\mathrm{CS}+\rightarrow \mathrm{US} \\
\mathrm{CS}-\mathrm{a} \rightarrow 1 \\
\mathrm{CS}-\mathrm{b} \rightarrow 1 \\
\mathrm{CS}-\mathrm{c} \rightarrow 1\end{array}$ \\
\hline & & - Contingency awareness \\
\hline Rating Phase & $2-3 \min$ & $\begin{array}{l}\text { - US-expectancy } \\
\text { - Fear } \\
\text { - Evaluation }\end{array}$ \\
\hline Extinction & $8 \min 33 s$ & $\begin{array}{l}\text { CS+ } \rightarrow 1 \\
\text { CS-a } \rightarrow 1 \\
\text { CS-b } \rightarrow 1 \\
\text { CS-c } \rightarrow 1\end{array}$ \\
\hline Rating Phase & $2-3 \min$ & $\begin{array}{l}\text { - US-expectancy } \\
\text { - Fear } \\
\text { - Evaluation }\end{array}$ \\
\hline (Extra Extinction) & $5 \min 43 s$ & $\begin{array}{l}C S+\rightarrow 1 \\
C S-a \rightarrow 1 \\
C S-b \rightarrow 1 \\
C S-c \rightarrow 1\end{array}$ \\
\hline (Rating Phase) & $2-3 \min$ & $\begin{array}{l}\text { - US-expectancy } \\
\text { - Fear } \\
\text { - Evaluation }\end{array}$ \\
\hline \multirow[t]{2}{*}{ Reinstatement } & $1 \mathrm{~min} 3 \mathrm{~s}$ & Reinstatement Group: 2 US- \\
\hline & $58 \mathrm{~s}$ & Control group: 4 tone probes \\
\hline Test & $44 \mathrm{~s}$ & $\begin{array}{l}\mathrm{CS}+\rightarrow 1 \\
\mathrm{CS}-\mathrm{a} \rightarrow 1\end{array}$ \\
\hline Rating Phase & $2-3 \min$ & $\begin{array}{l}\text { - US-expectancy } \\
\text { - Fear } \\
\text { - Evaluation }\end{array}$ \\
\hline
\end{tabular}

Figure 3 Schematic diagram of the different phases of the experiment.

did not show sufficient extinction in the US expectancy ratings, a second extinction phase was administered. Extra extinction trials were scheduled when the participant gave a postextinction US expectancy rating $\geq 50$ (on a scale ranging from zero to 100) for one or more of the CSs and/or when the difference in US expectancy between the CS+ and the CS-a was $\geq 40$ (for one participant, extra extinction trials were administered although this was not necessary according to the described criterion). This additional block of extinction trials consisted of eight unreinforced presentations of all four CSs.

The reinstatement phase differed according to the condition the participant was assigned to. The reinstatement group received two unpredicted USs. The first and second US were administered, respectively, 5 and $10 \mathrm{sec}$ after the onset of the phase. The control group did not receive any US presentations. No information was given with respect to the presence of USs during this phase. Four tones were administered in both groups to ensure that the participants remained trained in doing the secondary reaction time task. For the reinstatement group, these tones were presented $19.5,36.5,43.5$, and $55.5 \mathrm{sec}$ after the onset of the phase. In the control group, the tones were administered 14.5, $31.5,38.5$, and $50.5 \mathrm{sec}$ after phase onset. Approximately $5 \mathrm{sec}$ after the last tone probe, the first test trial was presented.

The final phase, the test phase, consisted of two presentation blocks. Each block consisted of one presentation of the CS+ and one presentation of the CS-a. The order of presentation was always the same for the two blocks but varied across participants. Because possible reinstatement effects could quickly diminish when tested under conditions of extinction, a probe was presented during all test trials. The CS+ and CS-a were each presented once with an early probe and once with a late probe.
Because the procedure we used is based on Hermans et al. (2004), we refer the reader to this article for a more detailed description of the procedure (e.g., the instructions that preceded the different phases and the ratings).

Next to the replication of the reinstatement effect in a direct measure (fear ratings), this study provided the first evidence for reinstatement of conditioned responses in humans in a measure that can not be susceptible to demand effects (the secondary reaction time task). These effects could not be replicated in the US expectancy ratings due to an increase in US expectancy associated with the CS-a after reinstatement that was not present in the control group. A possible explanation for this increase could be that participants get uncertain about what will happen after the reinstating USs and therefore consider all presented test stimuli as "dangerous."

In addition to the reinstatement effects in the fear ratings and the RT data, we found that the greater the difference in valence between the CS+ and CS-a was after extinction, the more reinstatement was observed in the reaction time task. These data provide clear evidence for reinstatement in humans and for the role of stimulus valence in the return of conditioned responses. Our data indicate that for the participants who received reinstating USs and thus (according to Bouton 1991) experience the context as dangerous, the extent to which they show reinstatement is related to the difference in valence between the CS+ and CS-a after extinction. These findings yield concrete starting points to attenuate reinstatement by acting on the evaluative meaning of stimuli.

\section{ACKNOWLEDGMENTS}

We would like to thank Ann Cuypers for running the experiment. D.V. is postdoctoral researcher for the Fund of Scientific Research FWO-Vlaanderen. This research was supported by a University of Leuven grant GOA/2001/01.

\section{REFERENCES}

Baeyens, F., Crombez, G., Van den Bergh, O., and Eelen, P. 1988. Once in contact always in contact: Evaluative conditioning is resistant to extinction. Adv. Behav. Res. Ther. 10: 179-199.

Bouton, M.E. 1991. Context and retrieval in extinction and in other examples of interference in simple associative learning. In Current topics in animal learning: Brain, emotion, and cognition (eds. L. Dachowski and C.F. Flaherty), pp. 25-53. Erlbaum, Hillsdale, NJ. - 2002. Context, ambiguity, and unlearning: Sources of relapse after behavioural extinction. Biol. Psych. 52: 976-986.

Bouton, M.E. and Bolles, R.C. 1979. Role of conditioned contextual stimuli in reinstatement of extinguished fear. J. Exp. Psychol. Anim. Behav. Process. 5: 368-378.

Dawson, M.E., Schell, A.M., Beers, J.R., and Kelly, A. 1982. Allocation of cognitive processing capacity during human autonomic classical conditioning. J. Exp. Psychol. 111: 273-295.

De Houwer, J., Thomas, S., and Baeyens, F. 2001. Associative learning of likes and dislikes: A review of 25 years of research on human evaluative conditioning. Psychol. Bull. 127: 853-869.

Delamater, A.R. 1997. Selective reinstatement of stimulus-outcome associations. Anim. Learn. Behav. 25: 400-412. 


\section{Dirikx et al.}

Elizalde, G. and Sclafani, A. 1990. Flavor preferences conditioned by intragastric polycose infusions: A detailed analysis using an electronic esphagus preparation. Physiol. Behav. 47: 63-77.

Hermans, D., Clarysse, J., Baeyens, F., and Spruyt, A. 2002a. Affect (version 3.0). http://www.psy.kuleuven.ac.be/leerpsy/affect. University of Leuven, Belgium.

Hermans, D., Crombez, G., Vansteenwegen, D., Baeyens, F., and Eelen, P. 2002b. Expectancy-learning and evaluative learning in human classical conditioning: Differential effects of extinction. In Advances in psychology research, Vol. 12, (ed. S.P. Shohov), pp.17-41. Nova Science Publishers, Inc., New York.

Hermans, D., Vansteenwegen, D., Crombez, G., Baeyens, F., and Eelen, P. 2002c. Expectancy-learning and evaluative learning in human classical conditioning: Affective priming as an indirect and unobtrusive measure of conditioned stimulus valence. Behav. Res.
Ther. 40: $217-234$.

Hermans, D., Dirikx, T., Vansteenwegen, D., Baeyens, F. and Eelen, P. 2004. Reinstatement of fear responses in human aversive conditioning. Behav. Res. Ther. (in press).

Lang, P.J. 1995. The emotion probe: Studies of motivation and attention. Am. Psychol. 50: 372-385.

Rescorla, R.A. 1996. Preservation of Pavlovian associations through extinction. Q. J. Exp. Psychol. 49B: 245-258.

Rescorla, R.A. and Heth, C.D. 1975. Reinstatement of fear to an extinguished conditioned stimulus. J. Exp. Psychol. Anim. Behav. Process. 104: 88-96.

Received April 2, 2004; accepted in revised form August 3, 2004. 


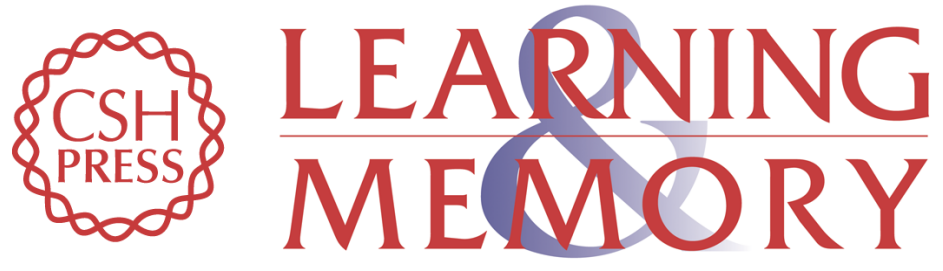

\section{Reinstatement of Extinguished Conditioned Responses and Negative Stimulus Valence as a Pathway to Return of Fear in Humans}

Trinette Dirikx, Dirk Hermans, Debora Vansteenwegen, et al.

Learn. Mem. 2004, 11:

Access the most recent version at doi:10.1101//m.78004

\section{License}

Email Alerting Receive free email alerts when new articles cite this article - sign up in the box at the Service top right corner of the article or click here. 